\title{
The disconnect between textbook and research: Inductive versus deductive approaches to grammar in first-year German college textbooks
}

\begin{abstract}
Foreign language teaching methodologies have changed noticeably in the last hundred years. The emphasis on grammar has decreased, while the focus on communication has increased. Rather than quantitative in nature, these changes concern themselves more with the qualitative question of how grammar is taught. Two common approaches to grammar teaching are the inductive and deductive approach. While they both fall under the explicit grammar-teaching umbrella, research strongly points toward an advantage of the inductive grammar teaching approach. Therefore, a principal question that this article seeks to answer is which approach is more commonly found in current first-year German college textbooks. A detailed analysis of how eleven relevant textbooks present their grammar lessons reveals that the overwhelming majority $(\mathrm{N}=8)$ of the textbooks use the deductive approach. These findings indicate a significant disconnect between grammar presentation in textbooks and recent research on successful and effective foreign language teaching. It is strongly recommended that textbook authors and colleagues involved in the textbook selection process be more informed with the research findings in SLA and be instrumental in seeing that these changes are reflected in textbooks and language teaching curricula.
\end{abstract}

KEYWORDS: inductive and deductive grammar, first-year German textbooks, the imperative, textbook selection.

\section{INTRODUCTION}

Changes in foreign language teaching methodologies have been driven, on the one hand, by new demands presented by learners (e.g., a greater need for conversational knowledge in the language as opposed to ability to read authors in the original language and translate texts) and, on the other hand, by advances and new findings regarding successful language learning in a growing number of subfields (such as foreign language teaching, second language acquisition, English as a second language, bilingualism, etc.). 
One of the more disputed aspects of foreign language teaching is grammar instruction. Its role and emphasis has indeed changed significantly over the last several decades. Grammar was at the center of the Grammar-Translation method (i.e., focus on form). But this teaching method fell out of favor, as it became clear that merely conjugating verbs correctly and memorizing vocabulary, without being able to formulate meaningful sentences, is unsatisfactory. The emphasis gradually shifted from grammar toward conversation skills with the advent of the Communicative Approach (i.e., focus on content). This, in turn, led to a pronounced emphasis on communication without focus on form, leading in part to fossilization of bad grammar habits in students (Richards \& Rogers 2001). So, language teachers found themselves back to paying more attention to grammar in the Post-Communicative Approach (i.e., focus on forms). Renewed attention to form is a reflection of the fact that, while using a communicative approach in teaching, one should not ignore accuracy. Or as Cohen (2009:4) quite elegantly concludes in his article arguing that we cannot have grammar and communication without each other, "Language is both rule-governed and creative. However, efforts to be creative without an underlying competence of the how and the why of rules, are akin to playing tennis with neither net or lines, that is to say, mere aimless chaos".

There are a number of variables that affect foreign language teaching. Among them are differences in learner types, learning goals, teaching materials, learning environment, and teacher beliefs. Nevertheless, while variation from class to class is to be expected, it is hoped that new findings regarding more successful teaching methods are reflected in textbooks and other teaching materials. However, from past research, we know that mainstream textbooks are very slow to integrate new findings from second language acquisition research (Tschirner 1998). Criticism of the grammar presentation in German college-level textbooks was also expressed by Rott (2000), who found that there is a disconnect between grammar and communication and that the instruction based on textbooks does not line up with pedagogical research. According to Magedanz (2008), grammar presentation and practice in textbooks do not promote proficiency skills as outlined by the ACTFL Guidelines. Roche and Suñer (2016) also draw attention to the lack of communication between the fields of language acquisition research and language pedagogy, resulting in the slow pace at which language classes and textbooks adopt new research findings in acquisition research.

On the above grounds, this article investigates the extent to which first-year German college textbooks reflect current findings in effective grammar teaching. On a broad and superficial level, we can distinguish between inductive 
and deductive foreign-language grammar teaching. However, it is useful to go beyond these two approaches and use other benchmarks for assessment. A list of criteria that reflect essential elements of integrated grammar teaching will be used to further evaluate textbooks that presently dominate the market.

\section{INDUCTIVE VERSUS DEDUCTIVE TEACHING OF GRAMMAR}

The debate around which method is better is not a new one, as we can surmise from Hammerly's (1975) book The deduction/induction controversy. Generally speaking, the inductive approach to teaching grammar consists of exposing students first to meaningful examples before they can discern patterns and make generalizations. The formulation of rules follows interaction with language, and it is a discovery-based learning method, or as Norris and Ortega (2000) put it, learners arrive at metalinguistic generalizations on their own. The deductive approach, on the other hand, presents the learner with the rule, and then students are to engage in language practice. Norris and Ortega (2000) place inductive and deductive teaching on a continuum of more explicit to less explicit instruction. In other words, both inductive and deductive teaching are explicit types of teaching, in opposition to implicit teaching, which does not present the learner with any kind of grammar explanation or rule formulation (cf. Tammenga-Helmantel, Arends \& Canrinus 2014, who conclude that any kind of grammar instruction has a positive effect on learning).

What does research say about the effectiveness of the two methods? While the specific methodologies vary somewhat among the studies that tested the inductive approach, there is strong evidence in its favor. For instance, Haight, Herron and Cole (2007) found that students in second-semester French courses did significantly better learning grammatical structures through the inductive approach than the deductive approach. Montazeran, Asadi and Maghsoudi (2014) also found that teaching countable and uncountable nouns to young learners of English as a foreign language yielded better results through the inductive method than through the deductive method. Similar were the findings in Tammenga-Helmantel, Bazhutkina, Hummel, Suhre and Steringa's (2016) study on Dutch students learning complex German grammatical structures and DeKeyser's (2003) study that found that the explicit-inductive group outperformed the explicit-deductive group on a grammaticality judgement test.

Some studies go beyond a binary consideration of the inductive versus the deductive method and consider other variables. Such is a study by Hwu (2014), in which she found that the inductive one worked better with high-aptitude 
learners and the deductive better with low-aptitude learners. Hwu's results corroborated earlier findings by Erlam (2005) and Shaffer (1989) which established a similar correlation between the teaching method and learner aptitude. Interesting is also a study conducted by Tammenga-Helmantel et al. (2014) who used inductive, deductive, implicit, and incidental grammar instruction when teaching adjectives in three different languages (English, German, and Spanish) to Dutch learners and obtained varying results for the three languages. The authors' main conclusion is that explicit instruction is definitely better than implicit instruction, but they also recommend the integration of varying forms of instruction for better results. Other studies that successfully used both inductive and deductive teaching to enhance learning are Ana and Ratminingsih (2012) and Widodo et al. (2006).

\section{BEYOND INDUCTIVE AND DEDUCTIVE}

We have seen so far that explicit grammar teaching is overall better than implicit teaching and that the inductive approach is generally more effective than the deductive approach. There are many other considerations that have been addressed recently in pedagogical research. For instance, findings show that successful teaching of grammar should be contextualized (Fehringer 2002; Omaggio Hadley 1993), include communicative activities (Rott 2000; Magedanz 2008), offer a sociocultural approach (Levine 2006), and be interactive and socially situated (Betz \& Huth 2014). Based on research by Lee and Van Patten (1995) and Swain (1993), Rott (2000) writes that a focus on grammatical form integrated in communication-oriented instruction is more effective. Lee and Van Patten (1995), similarly to Long and Robinson (1998), also make recommendations for sequencing activities from word to sentence to discourse levels, and they recommend generally focusing on only one new grammatical form. Oral and written modalities should also be chosen carefully and purposefully. Weber (2018), in her article on teaching grammar through literature, writes that linguistic competence and literary competence should be a single goal. Furthermore, Vyatkina $(2013,2020)$ recommends that we maintain a more holistic perspective toward grammar as a meaning-making resource, and she details a usage-based and corpus-based approach to grammar teaching. Numerous are also the studies that reach out to the use of multimedia and computer-assisted tools to teach grammar more effectively (Hoffman \& Wanner 2003; Kolesnikova 2012; Vyatkina 2013; Culman, Henry \& Van Patten 2009).

The cited studies are by no means prescriptive in nature. If there is one thing that these studies have in common, it is the recommendation to integrate grammar into language teaching and not to teach grammar for its own sake. Similarly, 
in the present study, in addition to evaluating the textbooks as to whether they use an inductive or deductive approach, assessment will be made of how well they integrate grammar into language teaching generally.

\section{COLLEGE-LEVEL FOREIGN LANGUAGE TEXTBOOKS}

Research analyzing foreign language textbooks is growing and is quite diverse. Looking across the languages, some studies on Spanish textbooks examined the presentation of the future tense (Orozco \& Thoms 2014) and articulatory phonetics (Arteaga 2000). A study on the typology of grammar activities in Italian textbooks conducted by Aski (2003) found that they still heavily rely on mechanical drills and are not reflective of the findings in research in second language acquisition. In comparison, Chapelle $(2009,2014)$ looked at how Canadian culture is represented in American French textbooks.

Examples from research on German textbooks include Vandergriff et al.'s (2008) study which analyzed gender-marking in seven first-year textbooks. The integration of pronunciation into German textbooks was explored by Müller (2008) and Pittman (2015). Furthermore, Snider (2005) compared communicative and non-communicative activities in six popular first-year German textbooks. He found that, while all textbooks claim to have a communicative approach, they still contain a significant amount of grammatical drills. Focus on form in and of itself is not bad, but research recommends that, even when students are focusing on grammatical accuracy, there should be meaning-based communication, and this was lacking from these grammatical drills. Furthermore, in response to students' growing interest in communication, textbooks have generally increased the amount of speaking practice/ activities. Interestingly though, a close analysis of all activities included in the six textbooks considered in Snider's (2005) study shows that they can be reduced to only a few types of activities, which were found to easily lead to a monotonous classroom experience. Another study on German first-year textbooks was conducted by Sippel and Nimmrichter (2017). It focused on students' perception of American versus Germany-published textbooks that differ both in methodology and in the presence or absence of English. They found no negative perception from students regarding the lack of English in the Germany-published textbooks. On the contrary, students reported the all-German textbooks as a welcome challenge. The authors conclude their article by recommending that German programs in the U.S. strongly consider adopting Germany-published textbooks in their curriculum. Other aspects of the textbooks that were analyzed include readings, culture, vocabulary, and ancillary materials. Particularly noteworthy is a study from 2000 by Olsen, who published 
a review of several first- and second-year textbooks based on 127 questionnaire responses from German college-level educators. Of all topics addressed in that survey, grammar was deemed the most problematic in terms of its presentation.

Textbooks represent an important component in the college-level foreign language learning experience. They are the result of the collaboration between one or several authors, generally professors in the field, and a publishing house. In terms of customers on the market, we can say that, while college professors are the main decision makers for textbook selection, students are in the end the ones purchasing the books. Research has also found that students' attitudes toward certain types of textbooks can influence their learning process (Edmonson \& Ward 2015). Furthermore, textbook prices, which are high and ever-growing, can sometimes be a factor that keeps students away from taking a language course (Sippel \& Nimmrichter 2017). When comparing U.S.-published German textbooks with Germany-published textbooks, Sippel and Nimmrichter found that the U.S.-published textbooks cost on the average $\$ 200$, which is significantly higher than the prices from the German publishers. In addition to the price difference, the authors give a favorable report from a pedagogical point of view about the two Germany-published books, compared to the two U.S.-published books. Particularly relevant to this article is their observation that American books use primarily the deductive method for teaching grammar, whereas the Germany-published books use the inductive method.

While the adoption of one particular textbook does not tell us to what extent and in what way the textbook is being used in the classroom, textbooks can still be broad indicators of current teaching methodologies in foreign languages. Guerrettaz and Johnston (2013) note that textbooks generally include both what is taught and how it is taught. However, they also call for more research on the connection between learning and class materials (including textbooks), and they call for the development of a theoretical framework for materials used. Hutchinson and Torres (1994), similarly to Masuhara and Tomlinson (2008), suggest that materials can act as agents of change by supporting novice teachers and can facilitate curricular change (Rubdy 2003). It is important to note, though, that oftentimes when changes in methodologies occur, teachers need appropriate training (Nur 2003), and oftentimes when the new course material does not match teachers' beliefs, expectations, and experience, the textbooks are not used as intended (Humphries 2014). One way of mitigating this would be to make sure to the people involved in the textbook selection process are more informed with current research (Angell, DuBravac \& Gonglewski 2008).

As we can see, there are many things to consider when we discuss collegelevel German textbooks. Some of these things have to do with their development, others with the selection process in a specific program, and others yet with their 
role in the teaching process. Given that decision makers in textbook selection can easily find themselves overwhelmed with choices, an overview of how first-year college level textbooks integrate grammar in light of new research findings is a needed contribution to the field.

\section{FIRST-YEAR GERMAN TEXTBOOKS}

The German college textbook market has been thriving for the last several decades, with many textbooks appearing in new editions every few years and with brand new textbooks frequently added to the market. Below is a representation of the most popular textbooks for first-year college German including the number of all printed editions (Table 1). The textbooks are listed in alphabetical order.

Table 1. Overview of the most popular textbooks for first-year college German

\begin{tabular}{|l|l|c|c|}
\hline \multicolumn{1}{|c|}{ Name of textbook } & \multicolumn{1}{|c|}{ Author(s) } & \multicolumn{1}{c|}{ Year(s) } & $\begin{array}{c}\text { Number } \\
\text { of editions }\end{array}$ \\
\hline 1. Deutsch heute & Jack Moeller et al. & $1974-2012$ & 10 \\
\hline 2. Deutsch, na klar! & Robert Di Donato et al. & $1990-2020$ & 8 \\
\hline 3. Kontakte & Erwin Tschirner et al. & $1988-2016$ & 8 \\
\hline 4. Netzwerk & Stefanie Dengler et al. & 2012,2021 & 2 \\
\hline 5. Neue Horizonte & David Dollenmayer et al. & $1984-2013$ & 8 \\
\hline 6. Sag mal & Christine Anton et al. & $2014-2021$ & 3 \\
\hline 7. Studio [21] & Funk and Kuhn & $2013-2015$ & 2 \\
\hline 8. Treffpunkt Deutsch & $\begin{array}{l}\text { Margaret T. Gonglewski, } \\
\text { E. Rosemarie Widmaier et al. }\end{array}$ & $1991-2018$ & 7 \\
\hline 9. Vorsprung & Thomas A. Lovik et al. & $1996-2020$ & 4 \\
\hline 10. Welten & Prisca Augustyn et al. & 2015 & 1 \\
\hline 11. Wie geht's? & Dieter Sevin et al. & $1980-2014$ & 10 \\
\hline
\end{tabular}

\subsection{Grammar in first-year German textbooks and the imperative}

This article seeks to answer the question whether first-year German textbooks follow the deductive or inductive approach and to examine how they integrate grammar within their chapters. Since textbook authors generally follow a certain language pedagogy philosophy and use it consistently in the book, the analysis in this article looks closely at how one representative grammar topic, the imperative, is introduced in first-year textbooks. Analyzing grammar integration by 
looking at one or a few selected grammar points is commonly done (Montazeran 2014; Tammenga-Helmantel et al. 2014; Orozco \& Toms 2014). The imperative was chosen as the focus of the present study for several reasons. It is different enough from the English imperative, it can be taught in several different ways, all textbooks introduce it in the first year of teaching, and while not particularly difficult, it is more complex in German than in English.

As we know, the imperative is used to express requests and commands or give directions and instructions. Speakers usually use the imperative when addressing one or several persons. Unlike English, which has one "you" form (used for both the singular and plural, informal and formal), German has the pronoun $d u$ for informal singular, ihr for informal plural, and Sie for formal singular and plural. Hence, there are three imperative forms that students have to learn. In addition to the general rules for the three different imperative forms, students need to pay attention to stem-changing verbs for the singular informal imperative. Additionally, the verb "to be" (Gr. sein) follows an irregular pattern in the imperative and is usually presented separately. The tables below (Table 2 and 3) shows the contrast between the English and German imperative using the regular verb "to go" (Gr. gehen) and the irregular verb "to speak" (Gr. sprechen).

Table 2. German and English Present tense and imperative conjugations of "to go"

\begin{tabular}{|l|l|l|l|}
\hline \multicolumn{2}{|c|}{ German - "gehen" } & \multicolumn{2}{c|}{ English - "to go" } \\
\hline Present simple tense & \multicolumn{1}{c|}{ Imperative } & Present simple tense & \multicolumn{1}{c|}{ Imperative } \\
\hline du gehst & Geh! & you go & Go \\
\hline ihr geht & Geht! & you go & Go \\
\hline Sie gehen & Gehen Sie! & you go & Go \\
\hline
\end{tabular}

Table 3. German and English Present tense and imperative conjugations of "to speak"

\begin{tabular}{|l|l|l|l|}
\hline \multicolumn{2}{|c|}{ German - "sprechen" } & \multicolumn{2}{c|}{ English - "to speak" } \\
\hline Present simple tense & \multicolumn{1}{c|}{ Imperative } & Present simple tense & \multicolumn{1}{c|}{ Imperative } \\
\hline du sprichst & Sprich! & you speak & Speak \\
\hline ihr sprecht & Sprecht! & you speak & Speak \\
\hline Sie sprechen & Sprechen Sie! & you speak & Speak \\
\hline
\end{tabular}

\subsection{Data collection}

The latest available copy of each textbook under analysis in this paper was used for this study. For each, the pages pertaining to the imperative were selected and photocopied for easier analysis. Some textbooks present the 
information regarding the imperative in one chapter, whereas others break it up across several. The pages selected for analysis include both the theoretical presentation of the grammar as well as exercises directly relevant to it. Furthermore, information regarding the articulation of the authors' pedagogical philosophy was gathered from the introductory pages of the textbooks. The information was tabulated and is presented in the table below (Table 4). It lists the name of the textbook and country of origin of the publishing house, year of latest edition, chapter(s) in which the imperative can be found (and total number of chapters in the textbook), method of grammar presentation (i.e., deductive or inductive), and general methodology of the textbook as articulated by the authors in the introductory pages. The number of pages of the grammar presentation proportionate to the total number of pages of the textbook is also calculated.

Table 4. Deductive or inductive approach for the Imperative

\begin{tabular}{|c|c|c|c|c|}
\hline $\begin{array}{c}\text { Textbook } \\
\text { (Publication Country/ } \\
\text { Year) }\end{array}$ & Chapter(s) & $\begin{array}{l}\text { Ind/ } \\
\text { Ded }\end{array}$ & Approach & $\begin{array}{c}\text { Pages of } \\
\text { Imperative/ } \\
\text { Textbook } \\
\text { Percent } \\
\end{array}$ \\
\hline $\begin{array}{l}\text { 1. Deutsch heute } \\
\text { (U.S./2012) }\end{array}$ & Ch. 3 (out of 12) & Ded & No information & $1 / 467(0,2 \%)$ \\
\hline $\begin{array}{l}\text { 2. Deutsch, na klar! } \\
\text { (U.S./2020) }\end{array}$ & Ch. 4 (out of 14 ) & Ded & $\begin{array}{l}\text { Authentic material, } \\
\text { communicative build- } \\
\text { ing blocks }\end{array}$ & $3 / 428(0,7 \%)$ \\
\hline $\begin{array}{ll}\text { 3. } & \text { Kontakte } \\
& \text { (U.S./2016) }\end{array}$ & $\begin{array}{l}\text { Intro A1, Ch. } 2 \& \\
\text { Ch. } 10 \text { (out of 12) }\end{array}$ & Ded & Natural approach & $11 / 431(2,6 \%)$ \\
\hline $\begin{array}{ll}\text { 4. } & \text { Netzwerk neu } \\
\text { (Germany/2021) }\end{array}$ & $\begin{array}{l}\text { Ch. } 3 \text { \& Ch. } 8 \\
\text { (out of 12) }\end{array}$ & Ind & $\begin{array}{l}\text { Authentic and inter- } \\
\text { active }\end{array}$ & $2 / 158(1,3 \%)$ \\
\hline $\begin{array}{ll}\text { 5. Neue Horizonte } \\
\text { (U.S.//2014) }\end{array}$ & Ch. 4 (out of 15) & Ded & $\begin{array}{l}\text { Communicative com- } \\
\text { petence }\end{array}$ & $6 / 445(1,3 \%)$ \\
\hline 6. Sag mal (U.S./2021) & Ch. 3 (out of 12) & Ded & Graphic intense & $4 / 538(0,7 \%)$ \\
\hline $\begin{array}{l}\text { 7. Studio [21] } \\
\text { (Germany/2015) }\end{array}$ & Ch. 12 (out of 12) & Ind & $\begin{array}{l}\text { Communicative, } \\
\text { interactive }\end{array}$ & $2 / 137(1,4 \%)$ \\
\hline $\begin{array}{l}\text { 8. Treffpunkt Deutsch } \\
\text { (U.S.//2019) }\end{array}$ & Ch. 4 (out of 12 ) & Ded & $\begin{array}{l}\text { Communicative } \\
\text { approach }\end{array}$ & $3 / 382(0,8 \%)$ \\
\hline $\begin{array}{l}\text { 9. Vorsprung } \\
\text { (U.S./ 2020) }\end{array}$ & $\begin{array}{l}\text { Ch. } 1 \text { \& Ch. } 4 \\
\text { (out of 12) }\end{array}$ & Ind & $\begin{array}{l}\text { Discovery learning, } \\
\text { explicit instruction }\end{array}$ & $7 / 486(1,4 \%)$ \\
\hline 10. Welten (U.S./2015) & Ch. 4 (out of 12) & Ded & $\begin{array}{l}\text { Functional, meaning- } \\
\text { ful tasks }\end{array}$ & $6 / 449(1,3 \%)$ \\
\hline $\begin{array}{l}\text { 11. Wie geht's } \\
\text { (U.S./2014) }\end{array}$ & Ch. 6 (out of 15 ) & Ded & $\begin{array}{l}\text { Balanced } 4 \text { language } \\
\text { skills }\end{array}$ & $2 / 449(0,4 \%)$ \\
\hline
\end{tabular}




\subsection{Data analysis}

As can be seen in Table 1, there is great variety in the publication years and number of editions of first-year German textbooks. There are textbooks that have been on the market for as long as 44 years (Deutsch heute) and with as many editions as ten (Deutsch heute and Vorsprung), and others that may have one or two editions (Netzwerk/Netzwerk neu and Welten, two fairly recent publications). Furthermore, of all eleven selected textbooks, there are nine that are published in the United States and two (Netzwerk/Netzwerk neu and Studio [21]) that are published by German publishing houses.

Eight of the eleven textbooks introduce the imperative in one chapter, and the other three break it up over several. Traditionally, first-year textbooks are used over the course of two semesters, and from the chapter number in which the imperative is taught, we can surmise whether it was to be taught in the first, second, or both semesters. All textbooks that teach the imperative in one chapter do it in the first half of the book, with the exception of Studio [21], which teaches it in chapter twelve, the last chapter of the book. From among the textbooks that divide it into several chapters, one textbook, Vorsprung, teaches it in two chapters in the first half of the book, and the other two, Kontakte and Netzwerk, spread it over two semesters. In the following paragraphs, details about the integration of the imperative are given for each textbook separately.

\section{Deutsch heute}

There is an introductory chapter and twelve further chapters in this book. Each chapter follows a similar format; namely, it is divided into a non-grammar part (including dialogues, vocabulary, and readings) and a grammar part. Throughout each chapter, there are four culture sections presented in English. The grammar part has anywhere between two and fifteen lessons with an average of eight per chapter. The imperative is introduced in Chapter three, as one of fifteen grammar lessons. There is one fill-in-the blank exercise prior to the grammar part, which includes a few informal singular imperatives. The exercise requires students to complete blanks with various active vocabulary from that chapter. Unless their attention were drawn to it, students would probably miss the fact that this exercise includes imperative forms. In the grammar section, first, the entire imperative paradigm is presented in a table using seven different regular and irregular verbs. Then, each form of the imperative (i.e., $d u$, ihr, and Sie) and the imperative of sein are presented in detail. The grammar explanation section is followed by one brief exercise where students are asked to give commands by transforming infinitives into the various imperative forms. 


\section{Deutsch, na klar!}

Every chapter in this textbook is clearly split up into two main parts: Wörter im Kontext (which includes three Themen) and Grammatik im Kontext (which includes anywhere between two and six grammar topics). Each chapter also has several Kultur sections, a Sprache im Kontext (which includes video activities and a reading), and a vocabulary list at the end. With the exception of one activity in Thema 3 asking students to match situations with suggestions that are phrased in the imperative, the entire imperative is restricted to the grammar section of Chapter four. First, the formal imperative is explained, followed by one listening exercise where students distinguish based on intonation whether a phrase is a question or a command. Then, the informal imperative is introduced, in singular and plural. Four exercises follow, in which students have to transform indicative sentences into imperative sentences, fill in the blanks with the imperative of sein (which is irregular), and come up with a list of possible commands given to a child. The next exercise, which appears to be part of the same unit, is an assignment wherein students create a podcast, but it has absolutely no relationship to the imperative or commands.

\section{Kontakte}

The textbook is divided into twelve chapters preceded by two introductory chapters. Each chapter is separated into non-grammar sections (including themes, culture, and readings) and a grammar section (including four to seven grammar topics). The formal imperative is introduced at the very beginning of the textbook in the form of common requests heard in the classroom. With the help of explanatory images and drawings and the recognition of cognates, students can successfully complete the exercises presented here. The separate grammar page starts out with an explanation in English of how formal requests are phrased in German, followed by another exercise that requires students to match requests with images. Chapter two introduces the informal singular imperative in the grammar section. There is no connection to the themes presented in the first part of the chapter. Following a concise explanation in English accompanied by examples, students are asked to complete a few exercises. The first one is a matching exercise, and the other two ask students to transform present tense indicative verbs and infinitives into imperatives. Chapter ten teaches giving directions, and students are given models with both the formal and informal imperative before being asked to practice giving directions with a partner. This lesson also introduces prepositions for giving directions, and the following exercise has a fill-in-the-blanks format where students need to fill in the correct preposition. The dialogues in the latter exercise include formal and informal (singular and 
plural) imperatives. The grammar section includes an extensive overview of the imperative, which reviews the formal and informal singular forms introduced earlier in the book, expanding upon them by introducing the informal plural, the first-person plural, and the irregular imperative forms of sein ("to be"). The three exercises that follow have students transform infinitives into imperatives and cover both formal and informal.

\section{Netzwerk neu}

This textbook published by Klett has twelve chapters, and each chapter opens with an introduction of relevant vocabulary followed by approximately five brief lessons. On the average, three grammar topics are integrated into some of these lessons, and each chapter ends with an interactive video lesson that has continuity throughout the entire book. The imperative is taught in Chapters three and eight. In Chapter three, the students learn how to give directions and are first exposed to imperatives in an audio exercise. At their second listening, they have to follow along on a map in the book. Then, they are given a very simple dialogue structure that includes "Gehen Sie" and are asked to practice with a partner. At this point, students are only taught how to use "gehen" and "fahren" in the imperative. A small grammar table with visual highlights provides the correct imperative forms of these two verbs. The next exercise has students work with a partner and practice giving each other directions with a map in the book. Chapter eight introduces imperatives with $d u$ and $i h r$ (and reviews the Sie-imperative). Students are exposed to several commands in the context of a fitness app that a character is using to become more active. Students are then asked to mark the imperative forms of the verbs in the exercise and to try to determine how imperatives with $d u$ are formed. Similar to what was seen in Chapter three, a table with visual highlights gives students the correct formation of the imperative of four verbs that are actively used in the lesson. Students are asked to practice several verbs with a partner. The next activity exposes students to imperatives with $i h r$ and Sie, and students are then asked to complete a table to formulate the rule for how these words are formed. Another exercise asks students to phrase a few requests appropriate for the classroom from a list of infinitives provided and share them with the class. In both chapters, we see imperatives also integrated at the end of the chapter in the video lesson.

\section{Neue Horizonte}

The textbook is divided into fifteen chapters, and each starts out with a few dialogues that introduce the topic of the chapter, followed by a page of relevant vocabulary and several interactive activities. A long section of grammar follows 
that includes between two and seven lessons. A reading section and a culture section conclude each chapter. The imperative is introduced in Chapter four. The dialogues at the opening of the chapter do contain a few imperatives, but unless the instructor draws students' attention to these forms, they will go unnoticed. The grammar section on the imperative includes separate sections on formal and informal as well as singular and plural (including the wir form), followed by a total of twelve exercises. Most of the exercises are set up as partner work, but basically all students have to do in these is to change a given infinitive into an imperative form. There are also a few exercises where students have to translate sentences from English into German and one where students have to come up with their own commands to each other.

\section{Sag mal}

This textbook has twelve chapters, and each chapter has two lessons. Each lesson starts out with a section that sets the context for the lesson. This is followed by pronunciation, the Fotoroman, culture, and grammar. The second lesson follows the same structure, and the entire chapter concludes with Panorama, which is another culture section, involving some reading, listening, and writing activities, as well as a glossary for the entire chapter. The imperative is taught in the second lesson of Chapter three. While a few imperative forms are included in the script of the Fotoroman, students' attention is not drawn to them. The entire paradigm of the imperative is laid out in the grammar section, and two pages of exercises follow. These are divided into application and communication exercises, which progress from using a mechanical infinitive, to following a conversional format in the imperative, to eliciting realistic commands in partner work. The lesson review also prompts students to work in pairs and plan a weekend trip with a friend, in which they would naturally use imperative forms.

\section{Studio [21]}

This textbook is divided into an introduction and twelve chapters. Each chapter has four to five lessons and two or three well-integrated grammar lessons. The imperative is taught in Chapter twelve. In it, students have to read a text and then use the Sie-imperative to make a list of the tips given. Another exercise asks them to match a problem in the indicative with a solution in the $d u$-imperative. Only then are students prompted to find more imperatives in the previous text and complete a table that summarizes the rule for the Sie and $d u$ imperatives. The next exercises present a few tips for non-smokers using the $i h r$-imperative. Students are asked to suggest more tips. Following this, they are prompted to complete a table with the rule for the $i h r$-imperative. 


\section{Treffpunkt}

Treffpunkt is divided into an introduction and twelve chapters. Each chapter includes sections on vocabulary, culture, grammar, and pronunciation. The grammar portion includes a total of five lessons on the average. The individual sections focus on a variety of things. The imperative is taught in the second section of Chapter four. Nothing prior to the grammar lesson includes any commands or imperative forms. The imperatives for Sie, ihr, and $d u$ are presented separately, and each section is followed by practice exercises. In these, students have to either match a problem with a suggestion or change an infinitive into an imperative. The last exercise of the grammar lesson merely has students recognize infinitive forms from some authentic German advertising.

\section{Vorsprung}

This textbook contains twelve chapters, and each chapter is divided into an Anlauf, Absprung, and Ziel section. Within the first two of these divisions, there are several grammar lessons, culture points, and colloquial German segments. Noteworthy are the Textdetektiv (text detective) sections, which serve as a metacognitive activity, guiding students to make connections between forms and structures taught and the intended meanings and usage of those forms and structures. These sections are embedded in the language lesson, prior to the explicit grammar sections. In Vorprung, the formal imperative is introduced in Chapter one and the informal (singular and plural) is taught in Chapter four. In both sections, there are imperative forms used in texts that lay the foundation for the lesson. The formal imperative exercises from Chapter one focus on passive understanding of requests and recognition of form. The Textdetektiv in Chapter four asks students to look back at the text and determine whether a certain imperative form is a command, apology, or inquiry. It also has them find more examples of commands and analyze their endings. Even in the grammar section, the imperative is introduced contextualized within the lesson, namely explaining that a character familiar to the students is using an informal form of a command. This same lesson introduces the $d u$, ihr, and wir imperative forms, and each section includes several exercises. One multiple-choice exercise has students match the correct response to a problem; another has students match a correct response to a problem and change an infinitive into an imperative; yet another has all four forms mixed together so that students need to determine which to use, changing an infinitive into the correct imperative; and the last exercise has students play "Simon says." At the end of the chapter, in the Ziel section, there is a communicative partner exercise where students play parent/child roles and give each other advice for a trip using imperatives. 


\section{Welten}

This textbook is divided into twelve chapters, each structured around one person. The chapters have four or five sections, and each section includes several texts and one or more grammar lessons. The imperative is taught in Chapter four. It is not clear why the imperative is taught in this chapter, since there is no imperative used in the chapter outside the grammar lesson. The grammar lesson explicitly presents the entire imperative paradigm including the $d u$, ihr, Sie, and wir forms, as well as the irregular imperative of sein and the fact the bitte is often used to make a command sound more polite. Four exercises follow, in which students must match problems with suggestions, transform infinitives or present tense indicatives into imperatives, and fill in the blanks with a correct imperative form, with no verb provided.

Wie geht's

This textbook starts out with five introductory sections called Schritte (steps), and the rest of the textbook is divided into fifteen chapters. Each chapter is broadly divided into three parts. The first presents the theme of the chapter and can include dialogues, exercises, and vocabulary lists. The second part of a chapter involves several grammar lessons, and the third is usually a reading section. The imperative is taught in Chapter six, without making any connection to the beginning of the chapter. The imperative is explained as having the $d u$, $i h r$, Sie, and wir forms. Three out of the four exercises have students transform given infinitives into imperatives, and the last activity asks students to come up with a list of commands and give them to a partner. At the end of the chapter, there is an activity that has students give advice to a friend having a hard time in college. Some helpful prompts are given, and students are also asked to use the imperative in this last exercise. They are then asked to give advice to an unknown audience using the formal imperative.

\subsection{Findings}

Using Norris and Ortega's (2000) distinction between an inductive (discovery-based) approach versus a deductive (grammar presentation followed by exercises) approach to grammar teaching, we find eight textbooks in the present study that use the deductive and three that use the inductive approach.

While there is some variation in the presentation, wording, and number of pages dedicated to the imperative, the eight textbooks that use the deductive approach generally follow the same pattern. There is a presentation of the grammatical rules of the imperative, and this is followed by a number of exercises to 
apply the new knowledge. The three remaining textbooks differ in their approach greatly from the other eight in that they present examples of the imperative first and then have students interact with the material and formulate the rules by themselves.

The authors' own wording used to describe the pedagogical philosophy of each textbook is somewhat harder to quantify and summarize. This is to be expected because each textbook, in order for it to "make it" on the market, needs to distinguish itself clearly from all the other textbooks already existent. Nevertheless, all textbooks describe themselves, broadly speaking, as communicative. While teaching grammar deductively cannot necessarily be labeled as non-communicative, it would be fair to say that it is less communicative than the inductive approach.

The percentage taken up by the sections addressing the imperative in each textbook varies between $0.4 \%$ and $2.6 \%$, with an average of $1.3 \%$ of the entire textbook (excluding introductory pages, appendices, and indexes).

\subsection{Suggestions for modifying deductive into inductive teaching}

This section will offer a few practical examples of how existing teaching of the imperative can be modified to a more inductive approach. Given the variety of presentations in the many textbooks analyzed above, we can think of a few broad guidelines as a starting point. First, instructors should avoid starting the lesson with an English presentation of the entire paradigm for the imperative. Instead, they should offer a few examples to the students that ideally tie into the theme of the chapter. For instance, Deutsch heute can use the topic of shopping as its context since the imperative is introduced in the chapter on "Eating and Shopping" (e.g., Was brauchen wir?; Kaufbitte Brot, Marmelade und Milch; or Geben Sie mir bitte zwei Orangen und drei Tomaten). The instructor can bring in pictures or toy foods, and comprehension can be tested by having brief dialogues where students ask for certain foods. In Neue Horizonte, the instructor can start out by pointing students to the imperative examples in the opening dialogue of the chapter. (e.g., Gehen Sie doch ohne mich; Warte mal!; Iss doch wenigstens ein Brötchen; Nimm doch das Brötchen mit.) A few examples in the Fotoroman in Sag mal can be used as the starting point for the imperative (e.g., Sei nicht traurig!; Sei nicht gemein!; Aber mach dir keine Sorgen.) Instructors who use Treffpunkt can use the information on modals and daily routines from Chapter four as a segue for the imperative. Students can be given a few examples of the imperative, such as Was sollen ich heute machen?; Geh ins Kino; Was soll ich heute essen?; and Iss eine Banane. In textbooks that teach the imperative in a chapter where it is more difficult to 
contextualize it, instructors can either use classroom TPR examples (e.g., Stehen Sie bitte auf!; Setzen Sie sich!; Schreiben Sie!; or Geh bitte zur Tafel!) or the teaching of the imperative can be moved to a chapter where the theme lends itself better to the use of commands (e.g., directions, shopping, advice, etc.). Once students see a few examples, they should be prompted to make observations about form and formulate the rule(s) for the imperative. In addition to further classroom and homework practice that allows students to practice several verbs and forms of the imperative, one important component at the end of the imperative unit should be free production of correct imperatives in meaningful contexts (e.g., planning a picnic or a party, asking for advice, giving each other directions, etc.).

\subsection{Discussion}

The major finding of this study is that the large majority of textbooks for introductory levels of college German use the deductive approach to grammar. Worth noting is the fact that two of the three textbooks that use an inductive approach are the two textbooks published in Germany. A plausible explanation for this correlation is that these two textbooks were originally created as second language textbooks. However, in recent years, Germany-published textbooks have been increasingly used outside of German-speaking countries in foreign language programs. By contrast, all textbooks that use a deductive approach are written for American students studying German as a foreign language in U.S. colleges. The first type of textbook sees its users as adults who live in a German-speaking country and who are driven by an integrative and instrumental motivation (see Gardner \& Lambert 1972) to learn the language as well as possible. The second type of textbook sees its users as learners of a foreign language who take classes on the average three days a week in an American college, some to fulfill a language requirement and others with a true desire to become fluent.

We saw in Section 2 of this article that previous research has found a significant advantage in teaching grammar using the inductive method compared to the deductive method. It is therefore surprising that such a small number of textbooks (and only one from among the U.S.-published ones) use the method that research shows to be more effective. It is important to remember that the quoted research discusses the teaching methods used in the classroom but does not specify how the grammar is presented in the teaching materials. In other words, one could still teach inductively from a textbook that presents the material deductively. It would be, however, more productive to teach inductively from a textbook that presents the material inductively too. 
The pedagogical philosophy articulated in the textbooks (including each U.S.-published book) generally indicates a communicative approach. Let us be reminded that deductive and inductive teaching methods are both classified as explicit grammar teaching and have been found more effective than implicit grammar teaching. However, research strongly points toward the inductive approach as being more effective in foreign language teaching. It is hoped that new textbooks and new editions of existing textbooks will take into consideration the latest findings in foreign language pedagogy and integrate grammar inductively.

\section{CONCLUSION}

The presentation of grammar in the first-year German college textbooks can be broadly divided into the deductive and the inductive approach. An analysis of the eleven textbooks (nine from American publishers and two published by German publishing houses) reveals that almost all American textbooks - the large majority of the books analyzed here - use the deductive approach, whereas only a minority - the ones published by German publishing houses and one published by an American publishing house - use the inductive approach. Research on many different languages has revealed a strong argument for the success of the inductive approach over the deductive approach. It is surprising, therefore, to see that textbook authors are maintaining grammar presentations from old editions and are not adapting the methodology of grammar presentation in recent editions to the latest findings in research on foreign language teaching. It is important that action be taken in order to align grammar presentations in textbooks with findings in SLA research. This can be achieved by ensuring that textbook authors and colleagues in the field who are involved in the textbook selection process stay informed with current methods and strategies in teaching pedagogy and that they be instrumental in implementing these changes in textbooks and language teaching curricula.

\section{REFERENCES}

Ana, K.T. / Ratminingsih, N.M. (2012). Teaching English tenses to EFL learners: Deductive or inductive? International Journal for Cross-Disciplinary Subjects in Education, 2 (2), 998-1004.

Angell, J. / DuBravac, S. / Gonglewski, M. (2008). Thinking globally, acting locally: Selecting textbooks for college-level language programs. Foreign Language Annals, 41, 562-573.

Arteaga, D.L. (2000). Articulatory phonetics in the first-year Spanish classroom. The Modern Language Journal, 84, 339-354.

Aski, J.M. (2003). Foreign language textbook activities: Keeping pace with second language acquisition research. Foreign Language Annals, 36, 57-65. 
Bai, X. / Luo, M. (2011). How much is trust worth? Evidence from the international online textbook market. Journal of Internet Commerce, 10 (4), 245-260.

Betz, E.M. / Huth, T. (2014). Beyond grammar: Teaching interaction in the German language classroom. Die Unterrichtspraxis/Teaching German, 47, 140-163.

Chapelle, C.A. (2009). A hidden curriculum in language textbooks: Are beginning learners of French at U.S. universities taught about Canada? The Modern Language Journal, 93 (2), 139-152.

Chapelle, C.A. (2014). Five decades of Canadian and Québec content in French textbooks in the United States. American Review of Canadian Studies, 44 (4), 415-432.

Cohen, Y. "Gerry" (2009). Grammar and communication: Can we real have one without the other? Babel, 43 (3), 4.

Culman, H. / Henry, N. / Van Patten, B. (2009). The role of explicit information in instructed SLA: An on-line study with processing instruction and German accusative case inflections. Die Unterrichtspraxis/Teaching German, 42 (1), 19-31.

DeKeyser, R.M. (2003). Implicit and explicit learning. In: C. Doughty / M. Long (eds.), The handbook of second language acquisition (pp. 313-348). Malden, MA: Blackwell.

Edmondson, D.R. / Ward, C. (2015). Students' attitudes towards textbook types: Are students really ready for e-textbooks? Atlantic Marketing Journal, 5 (1), 1-14.

Erlam, R. (2005). Language aptitude and its relationship to instructional effectiveness in second language acquisition. Language Teaching Research, 92, 147-71.

Fehringer, C. (2002). German grammar in context. London: Arnold.

Gardner, R.C. / Lambert, W. (1972). Attitudes and motivation in second language learning. Rowley, MA: Newbury House.

Guerrettaz, A.M. / Johnston, B. (2013). Materials in the classroom ecology. The Modern Language Journal, 97, 779-796.

Haight, C. / Herron, C. / Cole, S. (2007). The effects of deductive and guided inductive instructional approaches on the learning of grammar in the elementary foreign language college classroom. Foreign Language Annals, 40 (2), 288-310.

Hammerly, H. (1975). The deduction/induction controversy. The Modern Language Journal, 59 $(1-2), 15-18$.

Hoffmann, C. / Wanner, I. (2003). Multimedia authoring tools for German grammar. German as a Foreign Language, 2, 76-90.

Humphries, S. (2014). Factors influencing Japanese teachers' adoption of communication-oriented textbooks. In: S. Garton / K. Graves (eds.), International perspectives on materials in ELT. Basingstoke: Palgrave Macmillan.

Hutchinson, T. / Torres, E. (1994). The textbook as agent of change. ELT Journal, 48, 315-328.

Hwu, F. / Pan, W. / Sun, S. (2014) Aptitude-treatment interaction effects on explicit rule learning: A latent growth curve analysis. Language Teaching Research, 18 (3), 294-319.

Kolesnikova, A. (2012). Investigating effects of computer-based grammar tutorials [University of Iowa, UMI]. In: Dissertation Abstracts International, Section A: The Humanities and Social Sciences (vol. 72, Issue 12), 4432).

Lee, J.G. / Van Patten, B. (1995). Making communicative language teaching happen. New York: McGraw-Hill.

Levine, G. (2006). Problematizing the teaching and learning of grammar in the intermediate German classroom: A sociocultural approach. Die Unterrichtspraxis/Teaching German, 39 (1-2), 1-13.

Long, M.H. / Robinson, P. (1998). Focus on form: Theory, research, and practice. In: C. Doughty / J. Williams (eds.), Focus on form in classroom second language acquisition (pp. 15-41). Cambridge: Cambridge University Press.

Magedanz, J. (2008). A communicative approach to the passive in first-year German. Die Unterrichtspraxis/Teaching German, 37, 160-164. 
Masuhara, H. / Tomlinson, B. (2008). Materials for general English. In: B. Tomlinson (ed.), English language teaching materials: A critical review (pp. 17-37). London: Continuum.

Montazeran, P. / Asadi, E. / Maghsoudi, M. (2014). The effect of inductive and deductive methods of teaching on Iranian EFL learners' grammar knowledge. Enjoy Teaching Journal, 2 (3), 60-69.

Müller, M. (2008). Challenges and opportunities for methodologically principled L2 pronunciation training in German textbooks and class. Forum Deutsch, 16, 30-37.

Norris, J.M. / Ortega, L. (2000). Effectiveness of L2 instruction: A research synthesis and quantitative meta-analysis. Language Learning, 50, 417-528.

Nur, C. (2003). English language teaching in Indonesia: Changing policies and practical constraints. In: W.K. Ho / R.Y.L. Wong (eds.), English language teaching in East Asia today: Changing policies and practices (pp. 163-172). Singapore: Eastern Universities Press.

Olsen, S. (2000). First- and second-year textbooks: Which ones we use and how. Die Unterrichtspraxis/ Teaching German, 33 (2), 138-147.

Omaggio Hadley, A. (1993). Teaching languages in context. Boston, MA: Heinle \& Heinle.

Orozco, R. / Thoms, J.J. (2014). The future tense in Spanish L2 textbooks. Spanish. Context, 11 (1), 27-49.

Pittman, I. (2015). Integration of pronunciation in first-year German textbooks. In: J. Levis / R. Mohammad / M. Quian / Z. Zhou (eds.), Proceedings of the 6 th Pronunciation in second language learning and teaching conference (pp. 229-242). Ames, IA: Iowa State University.

Richards, J. / Rodgers, T. (2001). Approaches and methods in language teaching. New York: Cambridge University Press.

Roche, J. / Suñer, F. (2016). Metaphors and grammar teaching. Yearbook of the German Cognitive Linguistics Association, 4 (1), 89-112.

Rott, S. (2000). Teaching German grammar through communicative tasks: Some suggestions. Die Unterrichtspraxis/Teaching German, 33 (2), 125-133.

Rubdy, R. (2003). Selection of materials. In: B. Tomlinson (ed.), Developing materials for language teaching (pp. 37-57). London: Continuum.

Shaffer, C. (1989). A comparison of inductive and deductive approaches to teaching foreign languages. The Modern Language Journal, 73, 395-403.

Sippel, L. / Nimmrichter, S. (2017). Lehrwerke aus Deutschland: Eine Alternative für Anfängerkurse an US-Universitäten? Die Unterrichtspraxis/Teaching German, 50 (2), 198-212.

Snider, D. (2005). Communicative and non-communicative activities in first-year college German textbooks. Die Unterrichtspraxis/Teaching German, 38, 163-171.

Swain, M. (1993). The output hypothesis: Just speaking and writing aren't enough. The Canadian Modern Language Review, 50, 158-164.

Tammenga-Helmantel, M. / Arends, E. / Canrinus, E.T. (2014). The effectiveness of deductive, inductive, implicit and incidental grammatical instruction in second language classrooms. System, 45, 198-210.

Tammenga-Helmantel, M. / Bazhutkina, I. / Hummel, I. / Suhre, C. / Steringa, S. (2016). Comparing inductive and deductive grammatical instruction in teaching German as a foreign language in Dutch classrooms. System, 63, 101-114.

Tschirner, E. (1998). From lexicon to grammar. In: J. Harper / M. Lively / M. Williams (eds.), The coming age of the profession: Issues and emerging ideas for the teaching of foreign languages. Boston: Heinle \& Heinle.

Vandergriff, I. / Barry, D. / Mueller, K. (2008). Authentic models and usage norms? Gender marking in first-year textbooks. Die Unterrichtspraxis/Teaching German, 41, 144-150.

Vyatkina, N. (2013). Discovery learning and teaching with electronic corpora in an advanced German grammar course. Die Unterrichtspraxis/Teaching German, 46, 44-61. 
Vyatkina, N. (2020). Corpora as open educational resources for language teaching. Foreign Language Annals, 53 (2), 359-370.

Weber, A. (2018). Teaching grammar through literature in foreign language learning with German as an example. Per Linguam, 34, 77-89.

Widodo, H.P. (2006). Approaches and procedures for teaching grammar. English Teaching: Practice and Critique, 5 (1), 122-141.

Received: 02.04.2021; revised: 01.10.2021

IULIA PITTMAN

Auburn University pittman@auburn.edu

ORCID: 0000-0002-9474-438X 
